\title{
Designing a compact helmet for a motorcycle
}

\author{
Vitaly Gaevsky ${ }^{1}$, Tatiana Sidorenko ${ }^{1}$, Egor Andreev ${ }^{1}$, and Aanatoly Nefedkin ${ }^{1}$ \\ ${ }^{1}$ MADI, 125319, Moskva, Leningradskij prospekt, 64, Russia
}

\begin{abstract}
The paper considers the issues of increasing the passive safety of motor vehicles. The designs of modern helmets are shown, the positive and negative sides are considered, and the systems of their certification are considered. Aspects of creating compact helmets and a conceptual folding helmet are discussed. The design of a folding helmet, the material for making it, is proposed.
\end{abstract}

\section{Introduction}

In the modern world, motorcycles are in great demand. Safety can be provided by using the elements of passive safety - These are properties of the design of the motorcycle and equipment that prevent or decrease the severity of injuries to the rider, passengers and other road users after an accident has already occurred. Motorcycles have a weaker range of passive safety features less that of cars. Here passive safety is increased by the absence on the outer surface of sharp protrusions, corners, edges (for example, Brake \& Clutch Lever Ball Ends), the presence of energy-absorbing linings, secure load securing, the ability of rear-view mirrors to deform and break off without the formation of sharp protrusions and fragments. The equipment includes: body shield, motorcycle boots, gloves and a motorcycle helmet.

In the field of human safety, helmet-wearing is now required when riding a motorcycle, but everything else is optional. The main disadvantage of any modern helmet is its bulkiness. Because of this, the helmet is inconvenient to carry outside the motorcycle and it is almost impossible to have a spare helmet for the passenger, since there is nowhere to put it.

The purpose of the article is to develop proposals for creating a compact helmet that combines comfort, functionality and compactness without losing the properties of passive safety

\section{Statistics of road traffic accident}

From the statistical data for 2019, you can see that in Russia over the 8-month motorcycle season, the number of accidents with motorcyclists increased by $8 \%$ compared to the same period in 2018. In 3,328 cases of traffic accidents, 336 people have died and 3,589 people have been injured (refer to fig. 1a).

\footnotetext{
${ }^{*}$ Corresponding author: tasidorenko@gmail.com
} 
Motorcycle accidents happen for a variety of reasons. The most dangerous age of a person from the point of view of getting into an accident is 16-24 years old, at this age people more often neglect the rules of the road, safety measures. The high rates of accidents and fatalities associated with motorcycle accidents are determined primarily by poor road conditions, outdated road infrastructure design standards, and a weak driving culture. One of the most typical causes of accidents is collisions with cars, over more than half of all road traffic accidents. The other reasons are represented in Figure 1b.

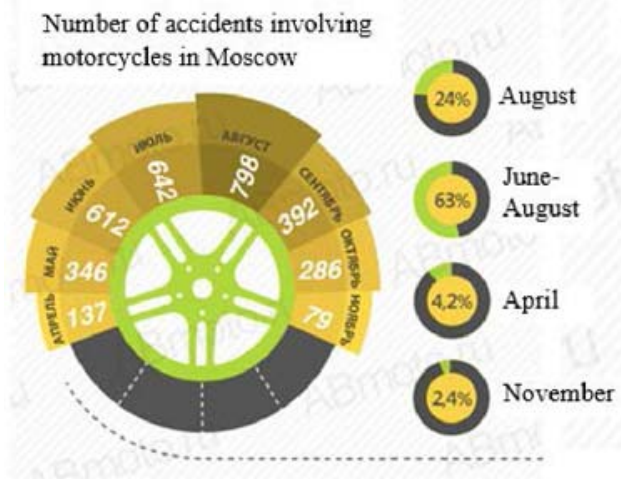

1a
The culprits of the motorcycle accident

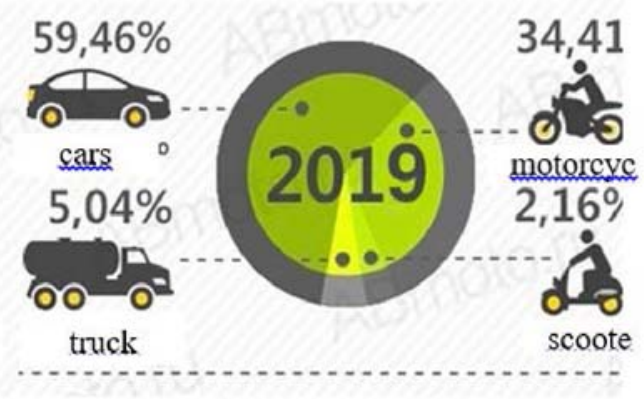

$1 b$

Fig. 1. Statistics of accidents involving motorcycles.

Active safety is implemented to prevent road traffic accidents $[1,2]$. It depends on factors such as the performance characteristics of the motorcycle, knowledge of the road rules, external factors, human factors, speed. But if active safety fails, and it is impossible to avoid an accident, then at the moment of an accident, the passive safety of the motorcycle comes into force.

Motorcycle passive safety is the Motorcycle's ability to reduce the severity of consequences in road traffic accidents. There are now examples of motorcycle airbags, roll safety bars, "roll cages," crash bars, sliders, additional lighting [3, 4] and other design features that can increase the chance of survival. But basically, passive safety consists of the right selection of motorcycle equipment. In most road traffic accidents, the clavicles, elbows, hips, knees, and head are injured. Injuries to the spine or head can adversely affect a person's health, the risk of death is very high. When minor accidents occur, leather jackets, gloves, motorcycle boots can be a kind of body shield.

Section 1.1 of the Road Traffic Licensing Laws (Licensing of Drivers) provides for the allocation of motorcycles to a separate category of transport vehicles (vehicles) for the driver's license category "A". Accordingly, when traveling on a motorcycle, moped, etc., Section 2.1.2 of the Traffic Code of states that a motorcycle helmet is mandatory when traveling on a motorcycle as a driver and as a passenger. The helmet must always be clamped when traveling [5].

Because of the road traffic accidents that occur with motorcyclists, it often happens that not only have to resort to medical care, but there are more serious effects [6]. Although the use of motorcycle safety gear can greatly reduce the chance of serious injury, but not everyone uses it.

A motorcycle helmet has a much more important function. Injuries to the occipital and temporal regions are more life-threatening than injuries to the face. According to statistics, only about $4 \%$ of all motorcycle accidents receive serious head injuries. Due to the small percentage, it may be a belief that such injuries are so rare that the helmet may not be worn at all. But that's not true. According to statistics (see Fig. 2), injuries can occur 
simultaneously, and the helmet in these situations simply serves its basic function, which is to save a person's life.

\section{The impact of equipment on injuries}

In an accident in 2019
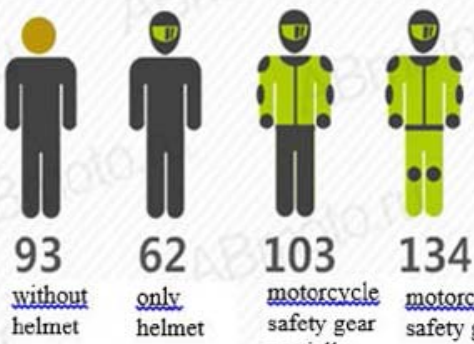

helmet

only. safety gear
partially

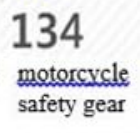

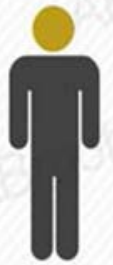

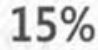

highest mortality

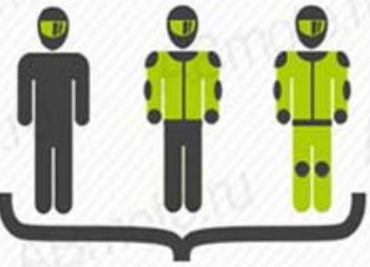

$6 \%$

in groups with a helmet, partial, full equipment, the mortality rate is lower

Fig. 2. The influence of equipment on injuries in road accidents.

After analyzing the given statistics, it is obvious that the least number of accidents is less likely to be caused by motorcyclists was wearing helmets. Road traffic accident deaths which occur without equipment (and especially without a helmet) are almost three times more common, because head injuries are the most common cause of death.

A modern motorcycle helmet is a sophisticated technological design that combines safety and comfort. It consists of many important parts (see Fig. 3a, 3b).

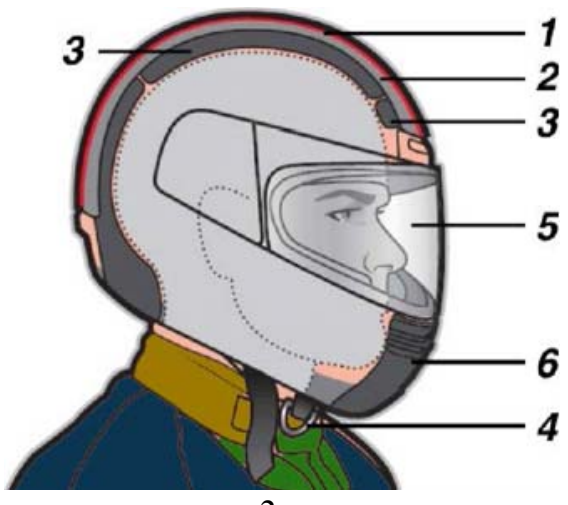

3a.

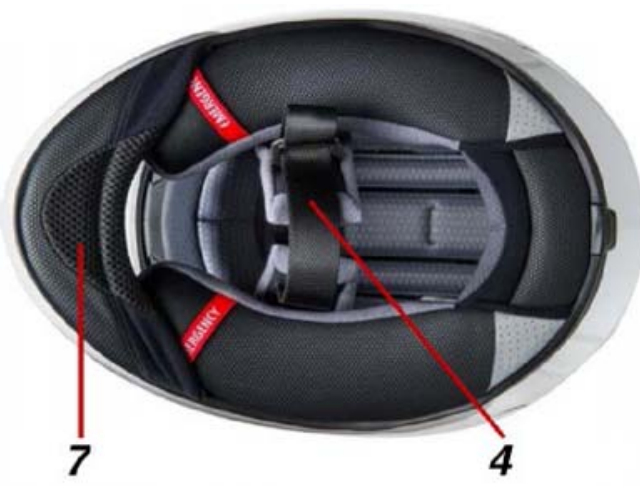

$3 b$.

Fig. 3. Helmet construction: 1 - "shell"; 2 - impact absorbing layer; 3 - interior decoration (comfort padding); 4 - clasp; 5 - visor- lens; 6 - breath deflector; 7 - Chin strap buckle

In total there are several types of helmets: open "half" and "three quarters"; cross; helmet for enduro and sports tourism; integral (full face); modular helmet (flip-up).

Each of the presented helmets has its own advantages and disadvantages, it is difficult to say which helmet is better or worse, it all depends on the type of motorcycle and the needs of the motorcyclist. A large number of sophisticated, "smart" helmets are currently being developed $[7,8]$ to increase the passive safety of the motorcyclist, but all of them remain oversized.

Since the helmet is the most important element of the passive safety of a motorcyclist, it is subject to mandatory certification in all countries of the world, including Russia.

There are several helmet standards certification systems in the world today: 
UN European Regulation № ECE R22.05 [7] is mandatory in Europe. The ECE 22.05 standard is mandatory in 50 countries worldwide and applies universally everywhere in the world. Currently, such tests on ECE 22.05 helmets of all kinds are the most advanced and realistic in the world and combine many techniques from other standards. After testing to ECE Standard 22.05, motorcycle helmets can be used in motorcycle racing circuit and offroad racing.

As there are no certified laboratories in Russia, helmets that have already been tested according to UN Regulation № ECE R22.05 are imported to Russia.

DOT (Department of transport) - standard set by the U.S. Department of Transportation in 1985, This is the Department of Transportation standard monitored by the National Highway Traffic Safety Administration (NHTSA).

It provides a minimum set of standards and safety features for helmets. The main difference between the DOT standard and ECE 22.05 is that helmets that receive European certification are tested before they go to the market and the customer can have no doubt about the safety of the helmet.

The SNELL certification was developed by the Snell Memorial Foundation, an American non-profit company, and was developed and named after motorcycle racer William "Pete" Snell. The criteria for this standard are less stringent (with less reality) than ECE 22.05, but the loyalties of the mandatory DOT standard have encouraged the development of more stringent alternative programs. Snell is not an official certification for motorcycle helmets, but the results of these tests are high safety ratings.

SHARP (Safety Helmet Assess ment and Rating Program) is a British rating system that gives scores based on its rating. When the UK joined the EU, it agreed to the ECE 22.05 standards, which are in force across Europe. Previously, British helmets were evaluated by the BSI rating system, a British evaluation system for already ECE 22.05 certified helmets, which was founded in the fall of 2007.

All of the above regulatory documents despite the differences agree on one thing: motorcycle helmets must be able to withstand a certain impact in different points of the outer shell, to be wear-resistant, in no case split into pieces with sharp edges, so as not to hurt the head of the motorcyclist and have an inner safe layer to soften the impact shock mitigation.

A recent study of motorcycle road traffic accidents in Germany by German professor Dietmar Otte shows how impacts are distributed over the motorcycle helmet in accidents (Figure 4). And an interesting fact was observed that a greater number of impacts occur on the chin portion, which is about $15-20 \%$.
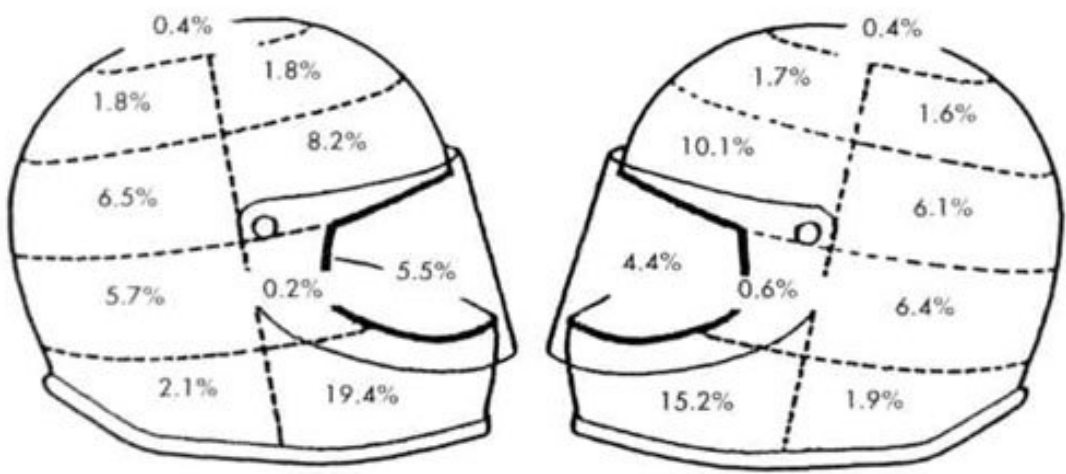

Fig. 4. Distribution of motorcycle helmet impacts in accidents. 
These studies have shown that helmets of the integral and modular types are best suited for greater protection of the motorcyclist's head. Although all other types of helmets are also suitable for certification and wearing.

\section{Designing a compact helmet for a motorcycle}

Helmets have been a size problem since their existence. Many motorcyclists are therefore in no particular hurry to wear helmets when driving motorcycles. In southern countries, such as Indonesia, the problem is generally considered a national one. The government cannot force people to wear helmets when riding motorcycles, more than $70 \%$ of all motorcyclists in Indonesia ride without a helmet. It seems to us that the creation of a compact but reliable helmet would solve this problem. Many people don't want to wear a helmet because they don't know where to put it when they walk, go to the office or store, it's very bulky and doesn't fit in any bag. If there were a helmet that could be stowed away in a carrying bag, many people would be happy to use it.

There is an Australian development, a folding motorcycle helmet called "Proteus" (see Figure 5), which has the look of a " three-quarter" helmet, it is foldable and relatively compact. [10] But that is where all its advantages end. It is quite complex in design, the collapse of the helmet is not complete, it is very expensive and at the same time does not protect the chin part of the motorcyclist's head. The main disadvantage of this folding helmet is the incompleteness of the structure from the standpoint compressive rigidity, this helmet can easily be crushed by lateral pressure.
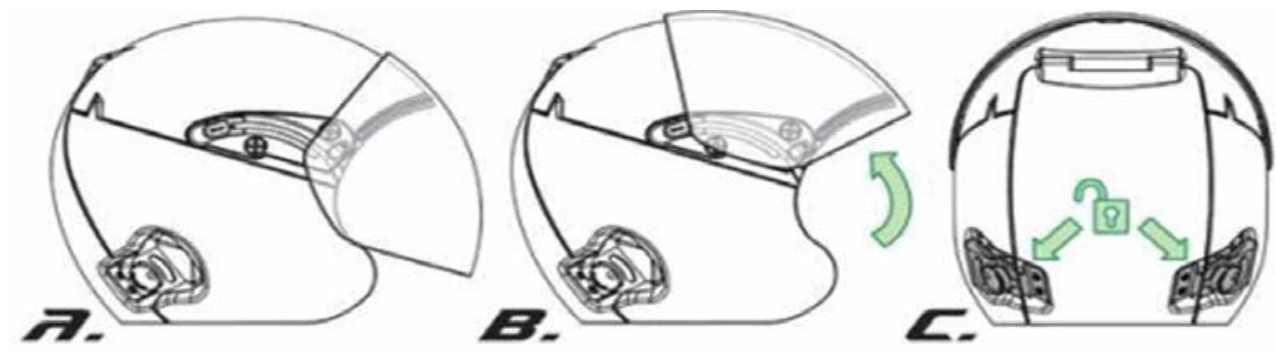

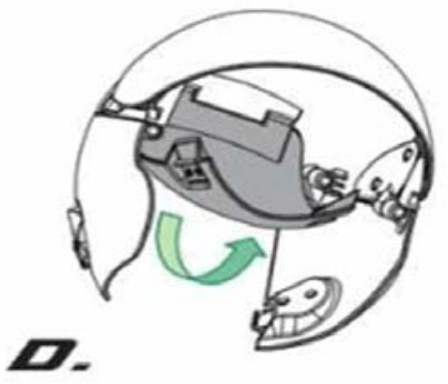

A. Helmet in its wearable form
D. Fold in back shell piece

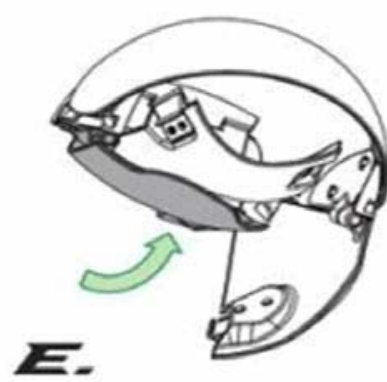

B. Visor is pushed up

E. Fold in right shell piece

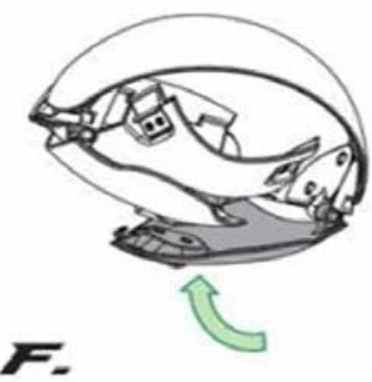

C. Unlock both latches

F. Fold in left shell piece

Fig. 5. Folding principle of the " Proteus " helmet.

If we use bionics, then among the animal world of our planet we can find a small inconspicuous globular armadillo (see Fig. 6). It was the origin of the concept of the folding helmet № 1, because its segmented "armor" folds one after another into a ball similar to a motorcycle helmet in case of danger. 

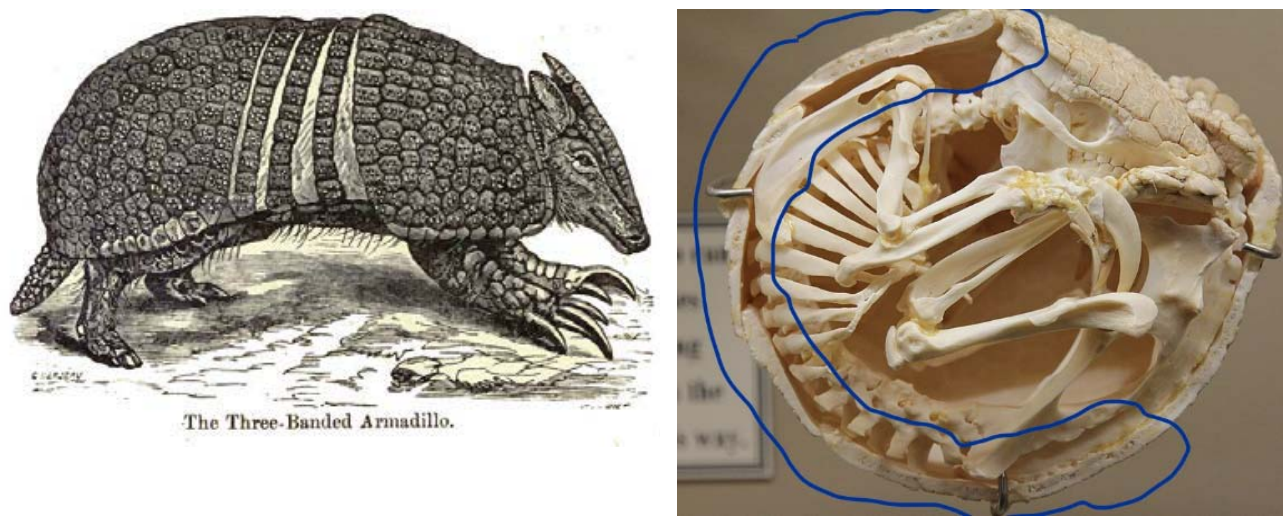

Fig. 6. The spherical armadillo and the scheme of its folding into a ball.

In order to calculate the size and number of segments, let's take the approximate dimensions of the helmet-integrity (Fig. 7).
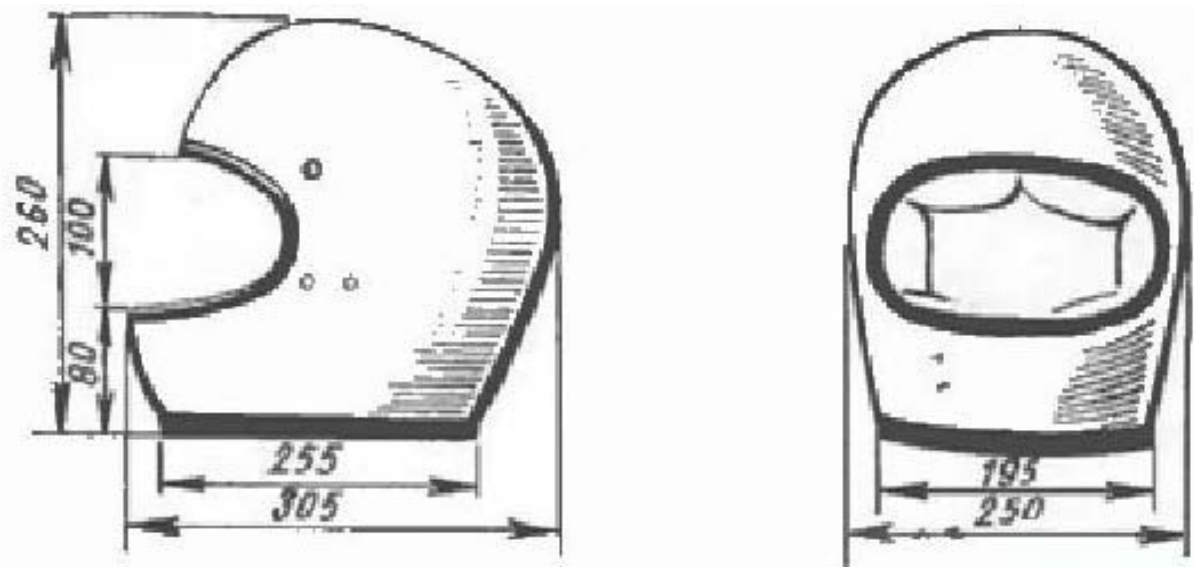

Fig. 7. Average dimensions of the helmet-integrity.

The arrangement of the helmet segments depends on the impact points in the tests required by UN Regulation No. ECE R22.05, the locations of which are shown in Figure 4. By assigning the impact points to the projected helmet, we assume that the folding helmet segments will be 4 pcs. (Fig. 8), and from these data we can calculate the area of all segments and the lower (non-separable part). 


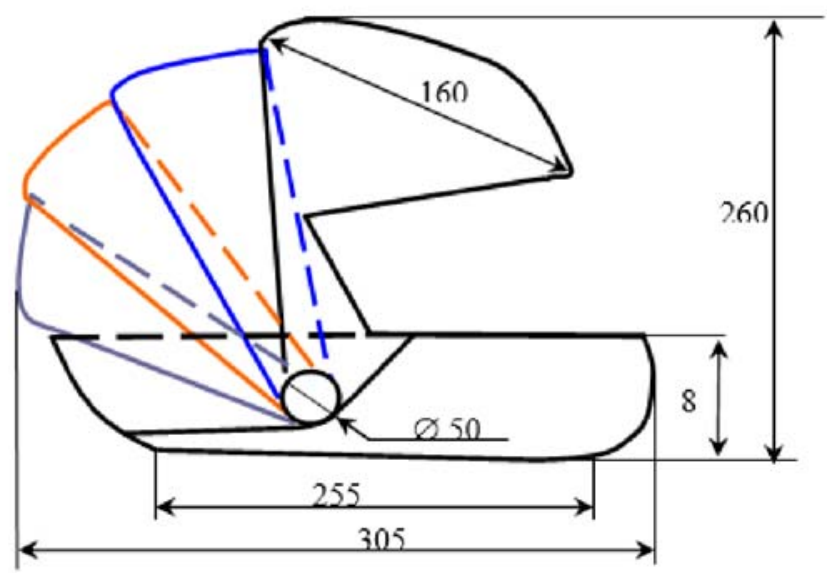

a)
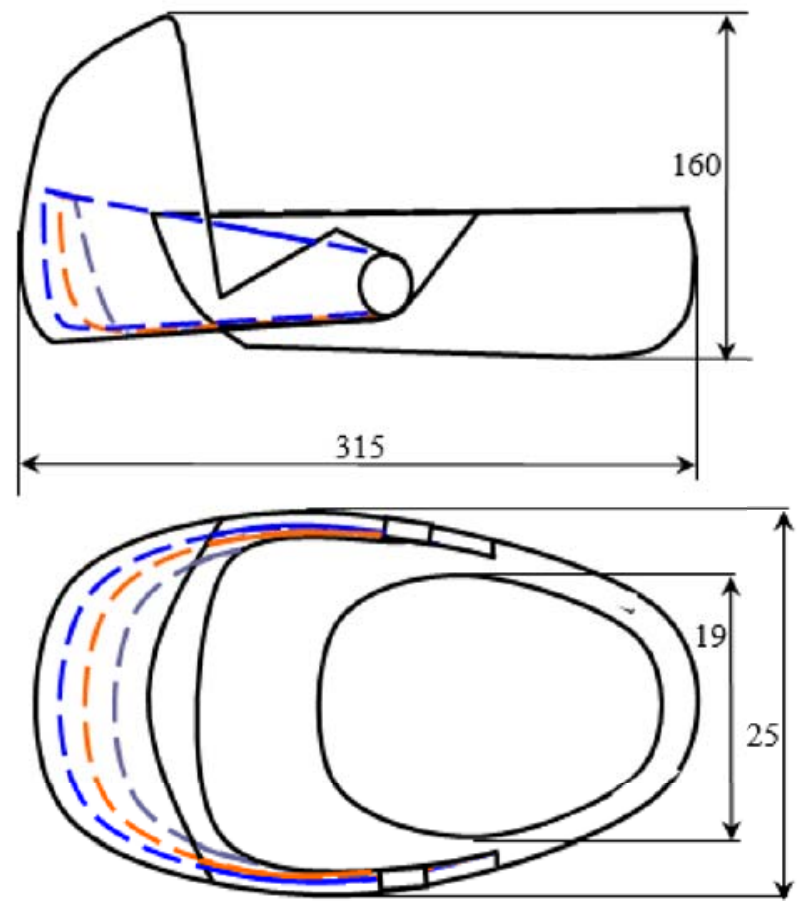

b)

Fig. 8. Conceptual folding helmet №1 in projections ( $\mathrm{a}$ - in working position and $\mathrm{b}$ - folded position).

To calculate the area of each segment, let's divide the helmet into elementary figures. It shows that the lower part is a parallelogram, the side upper segments are trapezoids and the tops of the upper segments are rectangles. The total area of the total external surface of the compact helmet equals $196600\left(\mathrm{~mm}^{2}\right)$. Since only flat shapes were calculated and all bends have been ignored, then including all the protrusions and convexities, then $200,000 \mathrm{~mm}^{2}$ is needed to produce one helmet. $\left(0,2 \mathrm{M}^{2}\right)$.

The choice of material is a fairly important part of manufacturing and designing a helmet, because it will affect how good the helmet has the ability to absorb the energy the impact and how much it will weigh. With the fact that today there are various innovative 
materials from which modern helmets are made and which can become a shell of a folding compact helmet, we will consider polycarbonate and carbon fiber, we can immediately agree that their use is about the same in terms of their effectiveness. Let's analyze the advantages and disadvantages of each material to determine the best option.

Table 2. Strength characteristics of monolithic polycarbonate and carbon fiber.

\begin{tabular}{|c|c|c|}
\hline Characteristics & $\begin{array}{c}\text { monolithic } \\
\text { polycarbonate }\end{array}$ & carbon fiber, \\
\hline Ultimate tensile strength $(\mathrm{UTS}), \mathrm{R}_{\mathrm{p}}, \mathrm{MPa}$ & 65 & 1000 \\
\hline Elastic tensile modulus, $\mathrm{E}_{\mathrm{p}}, \mathrm{MPa}$ & 2200 & 300000 \\
\hline Ultimate flexural strength, $\mathrm{R}_{\mathrm{u}}, \mathrm{MPa}$ & 100 & \\
\hline Elastic flexural modulus, $\mathrm{E}_{\mathrm{u}}, \mathrm{MPa}$ & 2350 & 250000 \\
\hline Ultimate compressive strength, $\mathrm{R}_{\mathrm{c}}, \mathrm{MPa}$ & 90 & 950 \\
\hline Density, $\mathrm{g} / \mathrm{cm}^{3}$ & 1,2 & 1,9 \\
\hline
\end{tabular}

If the mass of $1 \mathrm{~m}^{2}$ of polycarbonate with a thickness of $4 \mathrm{~mm}$ is $4.8 \mathrm{~kg}$, then, assuming that the area of the helmet is $0.2 \mathrm{~m}^{2}$, the total mass of the outer shell of the helmet will be $0.2 * 4.8=0.96 \mathrm{~kg}$

The mass of $1 \mathrm{~m}^{2}$ of finished carbon fiber (three-layer carbon fiber) (thickness $0.12 * 3=0.36 \mathrm{~mm})$ is $0.16 \mathrm{~kg}$. Accordingly, the mass of carbon plastic for the shell of the compact helmet will be $0,16^{*} 0,2=0,032 \mathrm{~kg}$. Since it is not a shell yet, we must add epoxy resin to it, so that the shape would harden. $900 \mathrm{~g}$ of epoxy resin must be spent for $1 \mathrm{~m}^{2}$ of carbon fiber reinforced plastic, then $0.2 * 900=450 \mathrm{~g}(0.45 \mathrm{~kg})$ is the total mass of resin to be used. Therefore, the mass of the outer shell will be $0.450 .032=0.482 \mathrm{~kg}$. (Carbon and epoxy resin).

By analyzing the data gathered about the two materials, we can conclude that polycarbonate strongly compromises with carbon fiber, because the most important material characteristic for a motorcycle helmet is the compressive strength of carbon fiber 10 times higher than the same limit for polycarbonate. Also, carbon fiber wins by mass indexes, the mass of the shell of the carbon fiber helmet was 2 times lighter. That is why the new compact motorcycle helmet must be made of carbon fiber.

Next comes the inner energy-absorbing layer (see Figure 3). In order for the helmet to be foldable, you need an energy absorbing layer that is soft, but resilient and durable. For this purpose, we suggest using polyurethane foam (synthetic foam material) (see Fig. 9), covered with a thin film of polyurethane for airproofing, and the principle of "self-inflating mat". The essence is that, after the strong mechanism of the "ratchet" type, the air valve is torn off, and the polyurethane foam, with air ducts inside, begins to be saturated with air. The channels are needed to reduce the weight of the material $\left(400 \mathrm{~g}\right.$ - mass of $\left.1 \mathrm{~m}^{2}\right)$ and to restore the original shape of the material in minimum time.

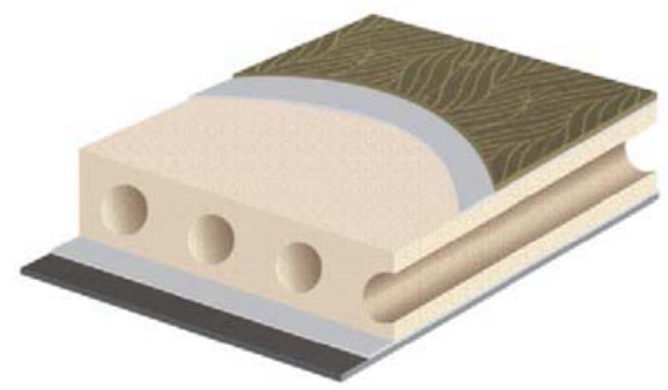

Fig. 9. Energy absorbing layer of polyurethane foam 
After calculating the outer shell of the helmet and analyzing the location of the energyabsorbing layer, we can say that it will be required about the same amount as the square meters used for the outer shell, i.e., $0.2 \mathrm{~m}^{2}$. Therefore, the mass of polyurethane foam in the helmet will be equal to $0.2 * 400=80 \mathrm{~g}(0.08 \mathrm{~kg})$. Therefore, the total mass of the helmet (without internal decoration) will be equal to $0.482+0.08=0.562 \mathrm{~kg}$.

At first sight it may seem that this layer is too soft for a motorcycle helmet and that today more rigid materials such as polystyrene foam (Styrofoam - foam plastic) are used. In fact, it is very confident to say that the new folding helmet, using a carbon outer shell and an inner polyurethane foam layer that has a compressive breaking stress of $1 \mathrm{MPa}$ and bending stress of $2 \mathrm{MPa}$, will conform to all the requirements of UN Regulation No. ECE 22.05 .

The last part of the helmet upgrade is the interior trim. It will have the ability to develop the fold inside the bottom of the helmet. The lining material will be hypoallergenic, antibacterial and removable for washing.

The design of folding helmet № 1 has a drawback, the visor does not allow the helmet to come together in one piece, it protrudes. And there is no visor, which protects a person at high speed.

Let's modernize the folding helmet №1. All materials and quantities are the same as in the design № 1, only with the addition of the mechanism for folding the frontal part, visor and visor pins are added (Fig. 10).

Design №2 is more convenient because the whole helmet will be assembled in one plane and it will not be clung by unnecessary protrusions, it will have less opportunity to break when folded, while this option is more effective in terms of safety. This kind of helmet is suitable for the use of all types of motorcycles. It may also be available with an extended protective chin bar and with a protective visor instead of a visor and this helmet may be used not only for everyday riding but also for cross-country riding.

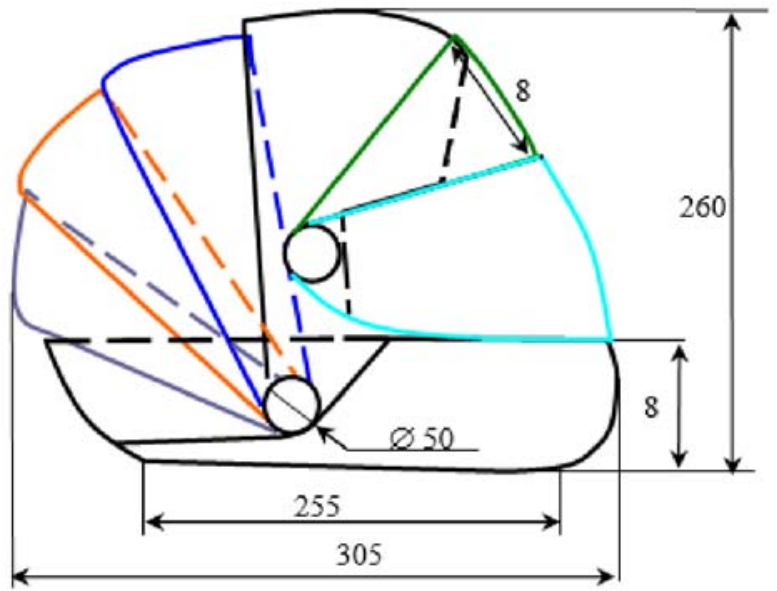

a)

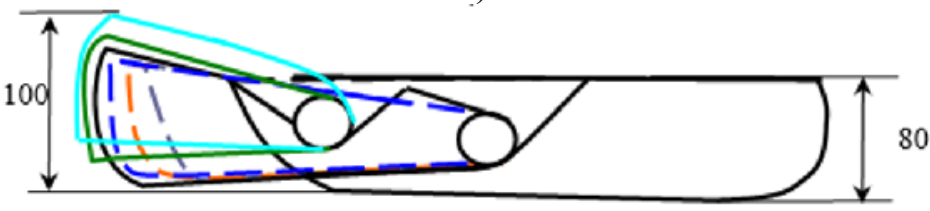

b)

Fig. 10. foldable helmet No. 2 ( $\mathrm{a}$ - in the form of using it, $\mathrm{b}$ - folded position) 


\section{Conclusions.}

Creating a compact, safety helmet will make it more attractive to use and encourage more people to wear helmets when driving motorcycles. When folded, it saves up to $50 \%$ of the volume occupied by the helmet in the operating position. An additional advantage of a folding helmet is that you can always carry a spare helmet with you for a potential passenger. Nowadays, if someone wants to be a passenger on a motorcycle is required to have their own helmet, the driver does not have the ability to carry a spare helmet because of the oversize.

\section{Reference}

1. V.V. Gaevskiy Problems of the application of intelligent driver assistance systems on a single-track vehicles. / V.V. Gaevskiy, A.M. Ivanov // (2018) IOP Conf. Ser.: Mater. Sci. Eng. 386012021

2. V.V. Gaevskiy The influence of the sliding friction coefficient on the stability of the movement of a single-track vehicle (STV) in a turn / V.V. Gaevskiy, I.V. Odinokova // Mechanization of construction - (2018), № 3, Moscow. pp. 32-35

3. Yu.V. Minakova, I.A. Novikov Methods of increasing the passive safety of two-wheeled motor vehicles // Modern materials, techniques and technologies. Transport, №1 (22), (2019), pp. 109-114.

4. Methodology for the assessment of wearable safety devices for motorcyclists' airbags based on finite element modeling (article)// International Journal of Impact Resistance Volume 26, Issue 1, (2021), pages 99-108// Trait Ballester, O., Llari, M., Arnoux, P.-J.

5. Decree of the Government of the Russian Federation of 23.10.1993 N 1090 (as amended of 31.12.2020) "On the Rules of the Road" (together with the "Basic Provisions for the Admission of Vehicles to Operation and the Responsibilities of Officials to Ensure Safety...

6. Are the motorcycles really "donor"? Examining Organ Donation Rates Between Helmets and Bikers (article)// Thorpe, SD ,Le, J., Adams, NS , Davis, AT , Gibson, CJ , Wright, GP , Rodriguez, CH , Krech, L. , Iskander G.A., Chapman, AJ //2020Journal of Safety Research Volume 75, December (2020), pages 173-177

7. Design and development of helmet to enhance human comfort and safety using FEA// International Conference on Frontiers in Automobile and Mechanical Engineering, FAME (2020), Volume 2311, Number 0500183// Subramanian, B., Sharma, G., Nambiar, R., Ramanathan, P., Shanmugam, V.

8. Smart helmet using advanced technology (conference presentation)Smart helmet using advanced technology (conference presentation) //Smart Innovation, Systems and Technologies Volume 195, 2021, pages 479-4884th International Conference on Information and Communication Technologies for Intelligent Systems, ICTIS 2020; Ahmedabad; India; From May 15, 2020 to May 16, (2020); Code 250649// Mooney Mohit Reddy,Venkata Krishna Rohit,Akash Reddy, Mamatha, I.

9. European UN Regulation No. ECE R22.05 "Uniform provisions concerning the approval of protective helmets and their visors for drivers and passengers of motorcycles and mopeds".

10. https://motocafe.ru/plug/4342-jessica-dunn-james-dyson-award-helmet.html. 